\title{
A Standard Reference Material for Calibration of the Cup Furnace Smoke Toxicity Method for Assessing the Acute Inhalation Toxicity of Combustion Products
}

Barbara C. Levin, Maya Paabo, and Susannah B. Schiller

National Institute of Standards and Technology, Gaithersburg, MD 20899
A standard reference material (SRM 1048) has been developed for use with the cup furnace smoke toxicity method. This SRM is to be used to calibrate the apparatus and to enable the user to have confidence that the method is being conducted in a correct manner and that the equipment is functioning properly. The toxicological results from this SRM should not be used to compare with those of other materials (i.e., to determine if the combustion products of a test material are more or less toxic than those from this SRM). SRM 1048 is an acrylonitrile-butadiene-styrene (ABS) and is the same as SRM 1007B which is used for calibrating the flaming mode of the Smoke Density Chamber test method (ASTM E-662 and NFPA 258). For the purposes of calibrating the cup furnace smoke toxicity method, $L C_{50}$ and N-Gas values plus their respective 95\% confidence limits have been determined and certified for two combustion modes (flaming and nonflaming) and two observation periods (for the $30 \mathrm{~min}$ exposure only and for the $30 \mathrm{~min}$ exposure plus a $14 \mathrm{~d}$ post-exposure period). The certified $L C_{50}$ values plus $95 \%$ confidence intervals (in $\left.\mathrm{g} / \mathrm{m}^{3}\right)$ are $27 \pm 3(30$ min, flaming); $25 \pm 3(30 \mathrm{~min}+14 \mathrm{~d}$, flaming); $58 \pm 15$ (30 min, nonflaming); and $53 \pm 12$ ( $30 \mathrm{~min}+14 \mathrm{~d}$, nonflaming). The certified $\mathrm{N}-\mathrm{G}$ as values plus $95 \%$ confidence intervals are $1.4 \pm 0.2$ (30 min, flaming); $1.5 \pm 0.2(30 \mathrm{~min}+14 \mathrm{~d}$, flaming); $1.2 \pm 0.2$ (30 min, nonflaming); and $1.4 \pm 0.2$ (30 min $+14 \mathrm{~d}$, nonflaming). It is recommended that this SRM be used with the N-Gas approach to calibrate the cup furnace smoke toxicity method rather than to determine the complete $L C_{50}$ values. The N-Gas approach has the advantage of providing information on the gases responsible for the lethalities as well as the toxic potency of the smoke. In addition, the $\mathrm{N}$ Gas approach reduces the number of experimental animals, the time necessary to complete the calibration, and the expense.

Key words: ABS; acrylonitrile-butadiene-styrene; combustion; combustion products; cup furnace; inhalation; SRM; standard reference material; toxicity tests.

Accepted: August 2, 1991

\section{Introduction}

The United States has one of the worst fire lethality rates in the industrialized world [1]. Eighty percent of these fire deaths are caused, not by burns, but by the inhalation of toxic smoke (gases plus particulates) [2]. The past decade has seen the development of a number of methods to measure the toxic potency of the combustion atmo- spheres produced from the thermal decomposition of materials [3]. In the United States, two of these methods have been used more extensively than the others. The first, known as the cup furnace smoke toxicity method $[4,5]$, was developed at the Center for Fire Research (CFR), National Bureau of Standards (NBS), now the Building and Fire Research 
Laboratory (BFRL), National Institute of Standards and Technology (NIST). The second was developed at the University of Pittsburgh under a grant from NIST and is called the University of Pittsburgh smoke toxicity method [6]. Neither the cup furnace smoke toxicity method nor the University of Pittsburgh smoke toxicity method have been accepted as standardized tests by ASTM or any other national or international scientific or technical society designed to develop standard test procedures. At the present time, the development of other smoke toxicity methods is still being actively pursued.

The number of smoke toxicity test apparatus users has increased. New York State has passed legislation requiring the testing of various materials before permitting their use in buildings [7]. Several other states are considering similar legislation. The test required by New York State is the one developed by the University of Pittsburgh. The U.S. Navy has recently specified the use of the cup furnace smoke toxicity apparatus for testing materials being considered for use in submarines [8]. A number of Federal agencies, industrial laboratories and testing companies are capable of conducting both test procedures.

Since the results of these smoke toxic potency tests, along with the results of other material flammability tests, are to be used in the decision making process regarding material selection and overall fire hazard, it is necessary to assure that such testing devices are installed and employed properly both by those laboratories currently conducting these tests and by new laboratories which enter the field. To help assure the reproducibility of results between laboratories, NIST has developed a SRM which can be used by all laboratories to calibrate the cup furnace smoke toxicity method. It is important to note that this SRM was not selected to represent the toxic potency of the combustion products of an "average" material and is not designed to be used for the comparison of the relative toxic potency of the combustion products of test materials. In other words, the toxic potency of the smoke from a test material should not be compared to the toxic potency of the smoke from this SRM.

The following criteria were used in the selection process of this SRM:

1. The material should have reproducible burning characteristics, regardless of the nature of the furnace (i.e., the material must be homogeneous and thus man-made).
2. The material should produce combustion products whose toxic potency values are within the range where the values for most materials are found.

3. Upon combustion, toxic gases in addition to $\mathrm{CO}$ should be generated and contribute to the lethal atmospheres.

4. The selected material should generate combustion products which cause deaths during the exposures or within $24 \mathrm{~h}$ following the exposures, since post-exposure deaths beyond this time are much less reproducible.

This report documents the research and development of a SRM for calibration of the overall test procedure and to assure that the cup furnace smoke toxicity apparatus is being used correctly. An acrylonitrile-butadiene-styrene (ABS) polymer whose characteristics fit the above criteria was selected. To perform this calibration, each laboratory would: 1 . determine the $L C_{50}$ values and compare them with the published certified $L C_{50}$ values or 2. determine the N-Gas values (at the published certified $L C_{50}$ values) and compare them with the certified N-Gas values. In the N-Gas approach, one or two animal tests are conducted at the certified $L C_{50}$ values to assure that some percentage (not 0 and not $100 \%$ ) of the animals respond. The calibration is conducted under two combustion modes (flaming and nonflaming) and two observation periods (a $30 \mathrm{~min}$ exposure and a $30 \mathrm{~min}$ exposure plus a $14 \mathrm{~d}$ post-exposure period). If the experimental values obtained by the laboratory fall within the $95 \%$ confidence intervals of the published certified values of this SRM, the investigator can be confident that the method is being conducted correctly.

\section{Materials and Methods}

\subsection{Materials}

A number of materials were screened before the decision to use an ABS polymer was made. The initial ABS that was selected for testing was standard reference material SRM 1007A used for calibrating the flaming mode in the ASTM E-662 and NFPA 258 test method to determine smoke density $[9,10]$. We found that this material exhibited suitable characteristics and fit the above criteria. However, during the experimental phase of this study, the stock of SRM 1007A was depleted. To conserve expense, the decision was made to obtain an ABS 
material suitable for SRMs for both the cup furnace smoke toxicity procedure and the smoke density chamber.

Three different ABS samples (ABS 2, ABS 3, and ABS 4) with formulations believed to be similar to SRM 1007A were sequentially prepared by a commercial manufacturer and tested in both the toxicity and smoke density apparatuses. Only ABS 4 proved to be suitable for both systems, and the manufacturer was asked to prepare a production lot, designated ABS 5 in this paper, for certification and sale as an SRM. ABS 4 and ABS 5 were thus presumably the same. In addition to acrylonitrile-butadiene-styrene, formulations 4 and 5 contained $6 \%$ titanium dioxide by weight. The ABS 5 was prepared by the manufacturer in sheets that were $254 \times 254 \mathrm{~mm}(10 \times 10 \mathrm{in})$ with a measured nominal thickness of $0.762 \mathrm{~mm}(0.030 \mathrm{in})$. The thickness was an important factor for the ASTM E-662 and NFPA 258 Smoke Density Chamber tests. The sheets of the production lot of ABS 5 were randomly numbered when received by NIST. The final cup furnace smoke toxicity SRM certified for sale is designated SRM 1048.

\subsection{Gases}

The cup furnace smoke toxicity method includes the chemical analysis of the following gases: $\mathrm{CO}$, $\mathrm{CO}_{2}, \mathrm{HCN}, \mathrm{O}_{2}, \mathrm{HCl}$, and $\mathrm{HBr}$. (The latter two halogen gases should be monitored if the material is known or suspected of generating these gases when thermally decomposed. The ABS samples tested for this SRM do not generate any $\mathrm{HCl}$ or $\mathrm{HBr}$.) If the instrumentation is available, the concentration of $\mathrm{NO}_{x}$ (both $\mathrm{NO}$ and $\mathrm{NO}_{2}$ ) may also be measured when nitrogen-containing materials, such as ABS, are being tested.

The calibration gases $\left(\mathrm{CO}, \mathrm{CO}_{2}, \mathrm{HCN}\right)$ utilized in the research and development of this SRM were commercially supplied in various concentrations in nitrogen. The concentrations of $\mathrm{HCN}$ in the commercially supplied cylinders were routinely checked by silver nitrate titration [11], since it is known that the concentration of $\mathrm{HCN}$ stored under these conditions will decrease with time. Nitric oxide (NO) in nitrogen, a standard reference material, was obtained from the Gas and Particulate Science Division, NIST.

Carbon monoxide and carbon dioxide were measured continuously during each test by non-dispersive infrared analyzers. Oxygen concentrations were measured continuously with a paramagnetic analyzer. Syringe samples $(100 \mu l)$ of the chamber atmosphere were analyzed for $\mathrm{HCN}$ approximately every $3 \mathrm{~min}$ with a gas chromatograph equipped with a thermionic detector [12]. The concentration of $\mathrm{NO}_{x}$ was measured continuously by a chemiluminescent $\mathrm{NO}_{x}$ analyzer with a sampling rate of 25 $\mathrm{ml} / \mathrm{min}$. All combustion products and gases (except $\mathrm{HCN}$ and $\mathrm{NO}_{x}$ ) that were removed for chemical analysis were returned to the chamber. The $\mathrm{CO}$, $\mathrm{CO}_{2}, \mathrm{O}_{2}$, and $\mathrm{NO}_{x}$ data were recorded by an on-line computer every $15 \mathrm{~s}$.

The presence of $\mathrm{HCN}$ in the combustion atmospheres interfered with the $\mathrm{NO}_{x}$ analysis when the chemiluminescent analyzer was equipped with a stainless steel converter. A change of the stainless steel converter to a molybdenum (Mo) converter (set at $375^{\circ} \mathrm{C}$ ) prevented this interference from $\mathrm{HCN}$. The amounts of $\mathrm{NO}$ and $\mathrm{NO}_{2}$ in the $\mathrm{NO}_{x}$ can be distinguished by allowing the sample gas to pass through the converter (gives results for total $\mathrm{NO}_{x}$ ) or to bypass the converter (gives only NO results). The amount of $\mathrm{NO}_{2}$ is calculated from the difference of the two signals.

For each experiment, the reported gas concentrations are the time-integrated average exposure values which were calculated by integrating the area under the instrument response curve and dividing by the exposure time (i.e., $(\mathrm{ppm} \times \mathrm{min}) / \mathrm{min}$ or, in the case of $\left.\mathrm{O}_{2},(\% \times \mathrm{min}) / \mathrm{min}\right)$. The calculated $\mathrm{CO}$ and $\mathrm{CO}_{2}$ concentrations are accurate to within 100 and $500 \mathrm{ppm}$, respectively. The calculated $\mathrm{HCN}$ concentrations are accurate to $10 \%$ of the $\mathrm{HCN}$ concentration. The calculated $\mathrm{NO}_{x}$ concentrations are accurate to $10 \%$ of the $\mathrm{NO}_{x}$ concentration.

\subsection{Animals}

Fischer 344 male rats, weighing $200-300 \mathrm{~g}$, were obtained from Taconic Farms (Germantown, NY)! They were allowed to acclimate to our laboratory conditions for at least $10 \mathrm{~d}$ prior to experimentation. Animal care and maintenance were performed in accordance with the procedures outlined in the National Institutes of Health's "Guide for the Care and Use of Laboratory Animals." Each rat was housed individually in suspended stainless steel cages and provided with food (Ralston Purina Rat Chow 5012) and water ad libitum. Twelve

\footnotetext{
${ }^{1}$ Certain commercial equipment, instruments, or materials are identified in this paper to specify adequately the experimental procedure. Such identification does not imply recommendation or endorsement by the National Institute of Standards and Technology, nor does it imply that the materials or equipment identified are necessarily the best available for the purpose.
} 
hours of fluorescent lighting per day were provided using an automatic timer.

\subsection{Cup Furnace Smoke Toxicity Procedure}

All exposures were conducted using the combustion system, the chemical analysis system, and the animal exposure system that were designed for the cup furnace smoke toxicity method [4]. Figures 1 and 2 are a diagram and schematic drawing of the experimental arrangement, respectively. The cup furnace is shown in Fig. 3. The samples were decomposed in the cup furnace located directly below the animal exposure chamber such that all the combustion products from the test sample evolved directly into the chamber. To prepare the test samples, the ABS sheets were cut into pieces approximately $2.54 \mathrm{~cm}^{2}\left(1 \mathrm{in}^{2}\right)$. Multiple squares were used to obtain the desired test concentration (defined as grams of material placed into the furnace divided by the exposure chamber volume in meters, i.e., $\mathrm{g} / \mathrm{m}^{3}$ or $\left.\mathrm{mg} / \mathrm{l}\right)$.

Tests were conducted in both flaming and nonflaming modes. The autoignition temperature of ABS was determined according to the procedure described in the cup furnace smoke toxicity method [4] and the furnace was set approximately $25^{\circ} \mathrm{C}$ below or above this autoignition temperature for the nonflaming or flaming modes, respectively. In the flaming tests, a sparker was also used to ensure that the ABS sample would flame as early as possi- ble. This sparker was not used in the determination of the autoignition temperature.

The cup furnace smoke toxicity method is a closed design in which all the gases and smoke are kept in a $200 \mathrm{~L}$ rectangular chamber for the duration of the experiment. Six rats are exposed in each experiment. Each animal is placed in a restrainer and inserted into one of six portholes located along the front of the exposure chamber such that only the heads of the animals are exposed. In the experiments conducted to determine $L C_{S 0}$ values, animal exposures started when the weighed sample was dropped into the preheated cup and continued for 30 min. The quartz cup which fits into the furnace and test specimen were weighed before and after the exposure to determine the mass of material consumed.

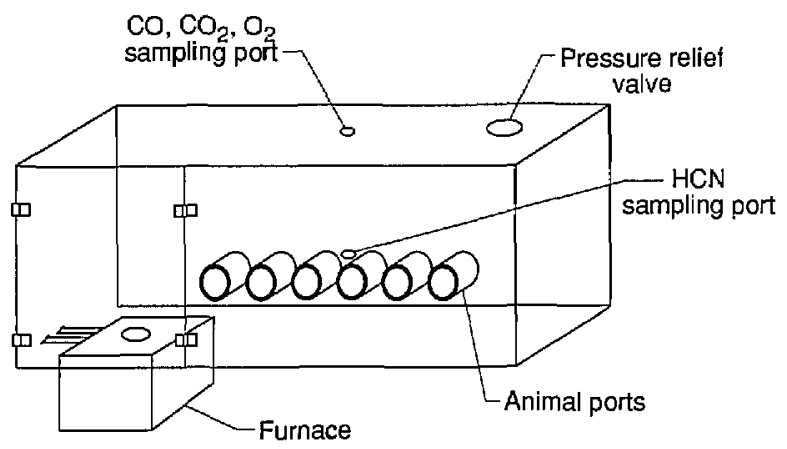

Fig. 1. Cup furnace smoke toxicity exposure chamber.

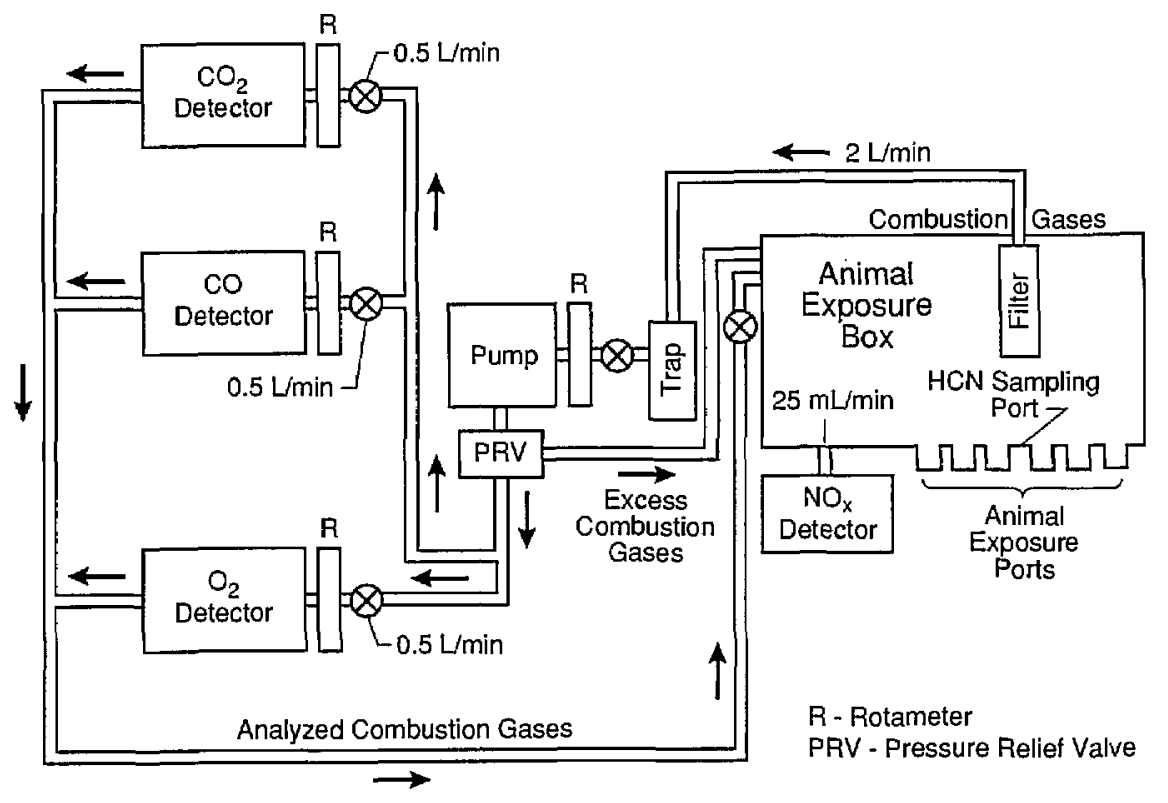

Fig. 2. Schematic of cup furnace smoke toxicity exposure chamber with attached analytical equipment. 


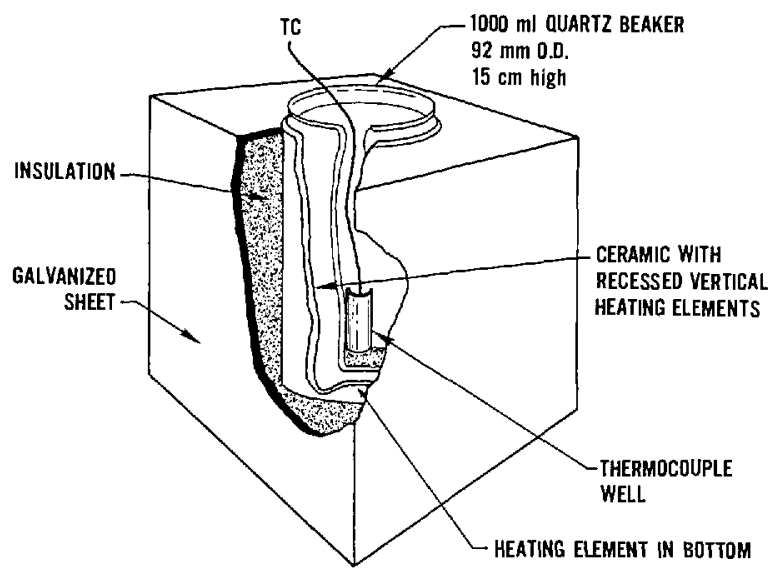

Fig. 3. Cup furnace.

The toxicological endpoint was death, which occurred either during the $\mathbf{3 0}$ min exposures or the 30 min exposure plus $14 \mathrm{~d}$ post-exposure observation period. $^{2}$ The percentage of animals dying at each fire effluent concentration was plotted to produce a concentration-response curve from which $L C_{50}$ values were calculated for both the $30 \mathrm{~min}$ exposures and for the $30 \mathrm{~min}$ plus $14 \mathrm{~d}$ post-exposure observation period. The $L C_{50}$ in these cases is defined as the mass of material placed in the furnace divided by the exposure chamber volume $\left(\mathrm{g} / \mathrm{m}^{3}\right)$ which caused $50 \%$ of the animals to die during the exposure only or during the exposure plus the $14 \mathrm{~d}$ post-exposure observation period. The $L C_{50}$ values and their $95 \%$ confidence limits shown in Tables 2 through 6 were calculated by the statistical method of Litchfield and Wilcoxon [13]. The $L C_{50}$ values provided in Tables 7 and 8 were calculated using probit analysis as described in Finney [14]. All animals (including the controls) were weighed daily from the day of arrival until the end of the $14 \mathrm{~d}$ post-exposure observation period.

\footnotetext{
${ }^{2}$ Under our experimental conditions, the rats exposed to the combustion products of ABS 5 died either during the exposure or within $24 \mathrm{~h}$. However, we routinely use a $14 \mathrm{~d}$ post-exposure observation period. If animals were to die during the $13 \mathrm{~d}$ period after the first $24 \mathrm{~h}$ following exposure to the ABS 5 smoke, it may be indicative that something in addition to the smoke exposure was affecting the animals (e.g., the animals may be harboring an unknown pathogen). This could be important information to prevent misinterpretation of one's data when similar deaths occur following exposures to the smoke from other materials.
}

\subsection{N-Gas Model Prediction}

The current N-Gas Model [15-18] equation is based on the studies at NIST of the toxicological interactions of six gases, $\mathrm{CO}, \mathrm{CO}_{2}, \mathrm{HCN}$, reduced $\mathrm{O}_{2}$, $\mathrm{HCl}$, and $\mathrm{HBr}$, and is used to estimate the amount of material (either loaded or consumed) necessary to produce an $L C_{50}$ for a $30 \mathrm{~min}$ exposure or a 30 min exposure plus a $14 \mathrm{~d}$ post-exposure period. $L C_{50}$ values for other exposure times can also be used. The model prediction is based on the following empirical mathematical relationship:

$$
\begin{gathered}
\text { N-Gas Value }=\frac{m[\mathrm{CO}]}{\left[\mathrm{CO}_{2}\right]-b}+\frac{[\mathrm{HCN}]}{L C_{50} \mathrm{HCN}} \\
+\frac{21-\left[\mathrm{O}_{2}\right]}{21-L C_{50} \mathrm{O}_{2}}+\frac{[\mathrm{HCl}]}{L C_{50} \mathrm{HCl}}+\frac{[\mathrm{HBr}]}{L C_{50} \mathrm{HBr}}
\end{gathered}
$$

where the numbers in brackets are time-integrated average atmospheric concentrations during a 30 min exposure period $\left[(\mathrm{ppm} \times \min ) / \mathrm{min}\right.$ or for $\mathrm{O}_{2}$ $(\% \times \mathrm{min}) / \mathrm{min}]$. We have found that $\mathrm{CO}_{2}$ acts synergistically with all toxic gases tested to date. However, empirically, we found that the $\mathrm{CO}_{2}$ term can be used in the equation only once. Therefore, the $\mathrm{CO}_{2}$ effect is utilized with the $\mathrm{CO}$ factor since $\mathrm{CO}$ is found in all fires and we have the most data on the $\mathrm{CO}$ and $\mathrm{CO}_{2}$ synergism [19]. As the concentration of $\mathrm{CO}_{2}$ increases [up to $50,000 \mathrm{ppm}(5 \%)$ ], the toxicity of CO increases. Above 50,000 ppm, the toxicity of $\mathrm{CO}$ starts to decrease again. The terms $m$ and $b$ define this synergistic interaction and equal -18 and 122000 , if the $\mathrm{CO}_{2}$ concentrations are $50,000 \mathrm{ppm}$ or less. For studies in which the $\mathrm{CO}_{2}$ concentrations are above 50,000 ppm, $m$ and $b$ equal 23 and -38600 , respectively. The $L C_{50}$ concentration of $\mathrm{HCN}$ is $200 \mathrm{ppm}$ for $30 \mathrm{~min}$ exposures or $150 \mathrm{ppm}$ for $30 \mathrm{~min}$ exposures plus $14 \mathrm{~d}$ post-exposure deaths. The $30 \mathrm{~min}$ exposure with or without the $14 \mathrm{~d}$ post-exposure $L C_{50}$ value for $\mathrm{O}_{2}$ is $5.4 \%$. Ideally, when this equation is unity, $50 \%$ of the animals should die. Examination of our animal lethality data for the three and four gas combinations indicate that the mean N-Gas value where animal deaths occur is 1.1 with a standard deviation of \pm 0.1 . We have found in the pure gas work that one half of the animals are likely to die when the N-Gas value is approximately 1.1 , no animals usually die below 0.9 and all the animals usually die above 1.3.

The N-Gas Model has been developed into an NGas Method for predicting the concentration of material which would produce an $L C_{50}[15,16]$. This 
method reduces the time necessary to evaluate a material and the number of test animals needed for the toxic potency determination. It also indicates whether the toxicity is usual (i.e., the toxicity can be explained by the measured gases) or is unusual (i.e., additional gases are needed to explain the toxicity). The N-Gas approach has been shown to work well under different combustion systems (radiant as well as convective heat sources; benchscale as well as full-scale room tests) [20-23].

To measure the toxic potency of a given material with this N-Gas Method, a sample is combusted under the conditions of concern (e.g., nonflaming or flaming) and the principal gaseous components $\left(\mathrm{CO}, \mathrm{CO}_{2}, \mathrm{HCN}\right.$, reduced $\mathrm{O}_{2}, \mathrm{HCl}$, and $\mathrm{HBr}$ ) of the smoke measured. Based on the results of the chemical analytical tests and the knowledge of the interactions of the measured gases, an estimated $L C_{50}$ value is calculated. If the N-Gas approach is to be used as a screening test, then in one or two further tests, six rats are exposed to the smoke from a sample of such size that the smoke should produce an atmosphere in which the $\mathrm{N}$-Gas value would be less than or equivalent to 0.8 . The deaths of some of the animals indicates the presence of one or more unknown toxicants. If more accuracy is needed, a detailed $L C_{50}$ can be determined. An $\mathrm{N}$-Gas value (at the $L C_{50}$ ) above 1.3 suggests that a toxicological antagonism is occurring.

The screening test, however, is not appropriate if one wants to use the N-Gas approach with the ABS SRM 1048 to calibrate the cup furnace smoke toxicity method. In this case, N-Gas values equivalent to the actual $L C_{50}$ S for the ABS SRM are provided in the SRM certificate. A sample mass equal to the certified $L C_{50}$ value is combusted under the conditions of concern (e.g., nonflaming or flaming) and the principal gaseous components $\left(\mathrm{CO}, \mathrm{CO}_{2}\right.$, $\mathrm{HCN}$, and reduced $\mathrm{O}_{2}$ ) of the ABS smoke measured. Equation (1) is then used to determine if this mass of material produced the gas concentrations necessary to achieve N-Gas values equivalent to those listed on the certificate. Finding N-Gas values within the $95 \%$ confidence limits of the certified values indicates the same concentration of material decomposes to produce a similar chemical atmosphere. To test if the toxicity is correct, the same mass of material (i.e., equal to the certified $\left.L C_{50}\right)$ is now used in one or two animal tests (NGas values are determined for these tests, too) in which the deaths of some percentage of the animals (not 0 and not 100\%) indicates that the results of the laboratory are close to that of the certified SRM. Four N-Gas values (i.e., flaming, 30 min exposure; flaming, 30 min exposure plus $14 \mathrm{~d}$ post-exposure observation period; nonflaming, 30 min exposure; nonflaming, $30 \mathrm{~min}$ exposure plus 14 d post-exposure observation period) and their equivalent $L C_{\text {so }}$ values are provided on the certificate and in Table 8 . If the values found by the investigator fall within the $95 \%$ confidence limits of the certified values, the equipment can be assumed to be working correctly.

\subsection{Comparison Factors in the Development of this SRM}

2.6.1 Autoignition Temperatures In the intralaboratory evaluation of the various ABS formulations, the autoignition temperatures were independently determined for each formulation and before each new series of experiments designed to determine an $L C_{50}$ value. Autoignition temperatures were also determined for ABS SRM $1007 \mathrm{~A}$ by each of the participants in the interlaboratory evaluation.

2.6.2 Interlaboratory Evaluation In the process of selecting the SRM, it was necessary to examine the reproducibility of results across laboratories using a comparable material. Therefore, three laboratories (in addition to NIST) were asked to participate in an interlaboratory evaluation of ABS 1007A using the cup furnace smoke toxicity method. The laboratories which tested this material were Mobay (Stilwell, KS), NIST (Gaithersburg, MD), Southwest Research Institute (San Antonio, TX), and U.S. Testing (Hoboken, NJ). They agreed to determine the autoignition temperatures and $L C_{50}$ values $(30 \mathrm{~min}$ exposures and $14 \mathrm{~d}$ post-exposure observation period) for both the flaming and nonflaming modes. The interlaboratory evaluation was designed and conducted before we realized that the supply of ABS 1007A was limited. Since the interlaboratory results on ABS 1007A showed good reproducibility and ABS 1007A and ABS 5 were considered comparable materials, an additional interlaboratory evaluation of ABS 5 was not considered necessary.

2.6.3 Intralaboratory Comparison NIST examined the repeatability of the $L C_{50}$ values (for both within the $30 \mathrm{~min}$ exposures and for within the $30 \mathrm{~min}$ exposures plus the $14 \mathrm{~d}$ post-exposure observation period). Enough tests were conducted to calculate three separate $L C_{50}$ values for each of the flaming and nonflaming modes of ABS 5 (the final selected $S R M$ ), two $L C_{50}$ values for each of the flaming and nonflaming modes of ABS sample $1007 \mathrm{~A}$, two $L C_{50}$ values for the flaming mode of 
ABS 4 , one $L C_{50}$ value for the nonflaming mode of ABS 4 , and one $L C_{50}$ value for the nonflaming mode of ABS 3. Since ABS 2 and 3 were found to be unsuitable for the Smoke Density Chamber, complete $L C_{50}$ values were not determined for every combustion mode.

2.6.4 N-Gas Values In the development of this SRM, both $L C_{50}$ and $N$-Gas values were obtained for each series of experiments. $\mathrm{N}$-gas prediction values at the $L C_{50}$ concentrations were calculated as follows: first, the N-Gas value was determined for each experiment using Eq. (1). Then these $\mathrm{N}$-gas values were plotted against their respective mass loading/chamber volumes. The best fit to the points was obtained by a least squares linear regression analysis. The N-Gas value at the $L C_{50}$ was then determined from the mass loading/ chamber volume equivalent to the experimentally determined $L C_{50}$.

2.6.5 Statistical Analysis All of the data from the 71 experiments that were conducted with ABS 5 were submitted to the Statistical Engineering Division in the Computing and Applied Mathematics Laboratory at NIST. The following measurements for each experiment were examined: the concentration of smoke [i.e., mass loading/chamber volume $\left.\left(\mathrm{g} / \mathrm{m}^{3}\right)\right]$ in the chamber, the number of rats that died during each $30 \mathrm{~min}$ exposure, the total number of rats that died during the 30 min exposures plus the post-exposure period of $14 \mathrm{~d}^{3}$ and the NGas values for the $30 \mathrm{~min}$ exposures and for the 30 min exposures plus the post-exposure period. Although more chemical analytical data was available, the "summary statistic" of the N-Gas values was sufficient to meet the goals of the analysis. The $30 \mathrm{~min}$ within-exposure and the $30 \mathrm{~min}$ within exposure plus post-exposure data were analyzed separately for both the flaming and nonflaming experiments.

Probit analysis as described in Finney [14] was used to determine the $L C_{50}$ values, the concentration at which $50 \%$ of the animals in such an experiment should die. Individual fits were done for each of the three series of experiments and the $L C_{50}$ values for each series was determined. N-Gas computations were also done on a series-by-series basis. A straight line through the origin was fit to the N-Gas values as a function of the concentration (i.e., mass of material loaded into the furnace per chamber volume) for each series. Then the $\mathrm{N}-\mathrm{Gas}$ value at

\footnotetext{
${ }^{3}$ All deaths occurred within the first $24 \mathrm{~h}$ following exposure, but surviving animals were kept and weighed for the full $14 \mathrm{~d}$ to assure no further deaths occurred.
}

the $L C_{50}$ for that series was calculated. Thus, three observations (one for each series) of the N-Gas value at the $L C_{50}$ for each combustion mode and observation period were obtained.

\section{Results}

\subsection{Autoignition Temperature}

The autoignition temperatures were determined for each tested formulation of ABS and three times for ABS 5 (once before each of the multiple series of tests on ABS 5) to examine the within laboratory repeatability (Table 1). Reproducibility between laboratories was tested only with ABS 1007A (Table 1). The interlaboratory evaluation was completed before we realized the stock of ABS SRM 1007 A was limited.

Table 1. Autoignition temperatures

\begin{tabular}{ccccc}
\hline \hline $\begin{array}{c}\text { ABS } \\
\text { designation }\end{array}$ & Laboratory & \multicolumn{3}{c}{ Autoignition temperatures $\left(^{\circ} \mathrm{C}\right)$} \\
& & Series $1^{\mathrm{a}}$ & Series $2^{\mathrm{a}}$ & Series 3 \\
\hline 1007A & NIST & 550 & & \\
$1007 \mathrm{~A}$ & $\# 4$ & $532-544$ & & \\
$1007 \mathrm{~A}$ & $\# 5$ & 515 & & \\
$1007 \mathrm{~A}$ & $\# 3$ & 500 & & \\
ABS 2 & NIST & $575^{\mathrm{b}}$ & & \\
ABS 3 & NIST & 550 & & 550 \\
ABS 4 & NIST & 550 & & 550 \\
ABS 5 & NIST & 550 & 550 \\
\hline
\end{tabular}

When the final ABS formulation was chosen, three series of separate experiments were conducted to examine the repeatability of results.

In the determination of the autoignition temperatures, $1 \mathrm{~g} \mathrm{sam}$ ples are tested to determine the temperature range. Then, an 8 $\mathrm{g}$ sample is tested to see if the higher loading will reduce the temperature. In the case of ABS 2, the amount of sample was limited, so the $8 \mathrm{~g}$ sample was not tested. ABS 2 proved to be unsuitable for the Smoke Density Chamber, so further testing was not pursued.

In the interlaboratory evaluation of $\mathrm{ABS} 1007 \mathrm{~A}$, NIST found an autoignition temperature of $550^{\circ} \mathrm{C}$ which was the same as that found by NIST for all the other ABS samples except \#2 (see Table 1). The other laboratories, however, found autoignition temperatures ranging from $500^{\circ} \mathrm{C}$ to $544^{\circ} \mathrm{C}$ for ABS 1007A. Although the autoignition temperatures were different, the $L C_{S 0}$ values that were determined by the other laboratories were in the same range (except for one laboratory in the flaming combustion mode) (see Table 2). The reasons for the differences in autoignition temperatures from 
the separate laboratories are unknown, but may be due to variations in furnace design, thermocouple placement, or the reference voltage of the thermocouple. Since the experiments are conducted at $25^{\circ} \mathrm{C}$ above and below the autoignition temperature of the SRM (i.e., the temperature of the experiments are normalized by the material), comparable toxicological data were obtained. This aspect of the interlaboratory evaluation indicated that the autoignition temperature should not be one of the certified values of this SRM, but rather each user should determine their own autoignition temperature of the SRM according to the procedure specified in Ref. [4]. In other words, the SRM should be tested in the flaming and nonflaming modes which are, respectively, $25^{\circ} \mathrm{C}$ above and below the autoignition temperature individually determined by each laboratory.

\subsection{Interlaboratory Evaluation}

All the toxicological and chemical data provided by the participants in the interlaboratory evaluation of ABS $1007 \mathrm{~A}$ were analyzed by NIST and the $L C_{50}$ s, $\mathrm{N}$-Gas values, and gas concentrations at the calculated $L C_{50}$ are given in Tables 2,3 , and 4. Each of these values are the result of multiple experiments.

Table 2. Interlaboratory evaluation of ABS 1007A. Toxicological data

\begin{tabular}{lll}
\hline \hline Laboratory & \multicolumn{2}{c}{$L C_{50}$ values } \\
& Nonflaming & \multicolumn{1}{c}{$\left(g / \mathrm{m}^{3}\right)$} \\
& & \multicolumn{1}{c}{ Flaming } \\
\hline NIST \#1 & $40(33-49)^{\mathrm{b}}$ & $25(21-29)$ \\
NIST \#2 & $37(32-43)$ & $26(24-29)$ \\
Laboratory \#3 & $34(24-47)$ & $\approx 25^{\mathrm{c}}\left[22.5^{\mathrm{d}}-25^{\mathrm{c}}\right]$ \\
Laboratory \#4 & $29(25-33)$ & $26(23-30)$ \\
Laboratory \#5 & $38^{\mathrm{f}}(33-43)$ & $41^{\mathrm{f}}(38-44)$
\end{tabular}

a Calculated based on deaths within the $30 \mathrm{~min}$ exposure plus the $14 \mathrm{~d}$ post-exposure observation period.

b $95 \%$ confidence limits, computed using the method of Litchfield and Wilcoxon [13].

${ }^{\mathrm{C}}$ Estimated from range of values, see footnotes $\mathrm{d}$ and $\mathrm{e}$.

${ }^{d} \mathrm{No}$ animals died at this concentration.

- Five out of the six exposed animals died at this concentration. ${ }^{\text {f }}$ These values were calculated at NIST in same manner as all other values in this table. Calculations by Laboratory \# 5 resulted in slightly lower values. (Nonflaming was $34 \mathrm{~g} / \mathrm{m}^{3}$ with $95 \%$ confidence limits of 30-38; flaming was $38 \mathrm{~g}^{3} \mathrm{~m}^{3}$ with $95 \%$ confidence limits of 32-41.)

Table 3. Interlaboratory evaluation of ABS 1007A. Nonflaming mode chemical data ${ }^{\mathrm{a}}$

\begin{tabular}{|c|c|c|c|c|c|c|}
\hline Lab \# & $\begin{array}{l}L C_{50} b^{b} \\
\left(g / \mathrm{m}^{3}\right)\end{array}$ & $\underset{(\mathrm{ppm})}{\mathrm{CO}}$ & $\begin{array}{c}\mathrm{CO}_{2} \\
(\mathrm{ppm})\end{array}$ & $\begin{array}{l}\mathrm{HCN} \\
(\mathrm{ppm})\end{array}$ & $\begin{array}{c}\mathrm{O}_{2} \\
(\%)\end{array}$ & $\begin{array}{l}\mathrm{N}-\mathrm{Gas} \\
\text { value }\end{array}$ \\
\hline NIST \#1 & $\begin{array}{c}40 \\
(33-49)^{c}\end{array}$ & $\begin{array}{c}450 \\
(370-550)^{d}\end{array}$ & $\begin{array}{c}2960 \\
(2610-3410)\end{array}$ & $\begin{array}{c}170 \\
(140-200)\end{array}$ & $\begin{array}{c}20.5 \\
(20.5-20.4)\end{array}$ & $\begin{array}{c}1.2^{\mathrm{e}} \\
(1.0-1.5) \\
1.2^{\mathrm{f}}\end{array}$ \\
\hline NIST $\# 2$ & $\begin{array}{c}37 \\
(32-43)\end{array}$ & $\begin{array}{c}440 \\
(380-580)\end{array}$ & $\begin{array}{c}3800 \\
(3340-4350)\end{array}$ & $\begin{array}{c}180 \\
(150-210)\end{array}$ & $\begin{array}{c}20.4 \\
(20.5-20.3)\end{array}$ & $\begin{array}{c}1.3^{\mathrm{c}} \\
(1.1-1.5) \\
1.3^{\mathrm{f}}\end{array}$ \\
\hline $\mathrm{Lab} \# 3$ & $\begin{array}{c}34 \\
(24-47)\end{array}$ & $\mathrm{NDP}^{\mathrm{h}}$ & NDP & NDP & NDP & NDP \\
\hline $\mathrm{Lab} \# 4$ & $\begin{array}{c}29 \\
(25-33)\end{array}$ & $\begin{array}{c}710 \\
(610-800)\end{array}$ & $\begin{array}{c}7410 \\
(6520-8300)\end{array}$ & $\begin{array}{c}150 \\
(130-170)\end{array}$ & $\begin{array}{c}20.0 \\
(20.1-19.9)\end{array}$ & $\begin{array}{c}1.2^{\mathrm{c}} \\
(1.1-1.3) \\
1.1^{\mathrm{f}}\end{array}$ \\
\hline Lab \#5 & $\begin{array}{c}38 \\
(33-44)\end{array}$ & $\begin{array}{c}420 \\
(360-490)\end{array}$ & $\begin{array}{c}2270 \\
(2140-2440)\end{array}$ & $N M^{i}$ & $\begin{array}{c}20.5 \\
(20.5-20.4)\end{array}$ & $\mathrm{NC}^{j}$ \\
\hline
\end{tabular}

\footnotetext{
- Time-integrated average concentration over the $30 \mathrm{~min}$ exposure period calculated at the $L C_{50}$ value. Based on the least squares analysis of the average $30 \mathrm{~min}$ gas concentrations at each mass loading tested.

b Based on deaths which occurred within- and post-exposure.

- 95\% confidence limits on $L C_{50}$ value, computed using the method of Litchfield and Wilcoxon [13].

The gas concentrations calculated at the low and high $95 \%$ confidence limits of the $L C_{50}$.

'Based on a least squares analysis of the $\mathrm{N}$-Gas values for each experiment as a function of the mass loading. $\mathrm{N}$-Gas value is that found at the $L C_{50}$.

${ }^{t}$ Based on gas concentrations provided in this table.

${ }^{b}$ NDP $\rightarrow$ no data provided.

i $\mathrm{NM} \rightarrow$ not measured.

i $\mathrm{NC}-$ not calculated due to lack of HCN data.
} 
Table 4. Interlaboratory evaluation of ABS 1007A. Flaming mode chemical data"

\begin{tabular}{|c|c|c|c|c|c|c|}
\hline Lab \# & $\begin{array}{l}L C_{50}{ }^{b} \\
\left(\mathrm{~g} / \mathrm{m}^{3}\right)\end{array}$ & $\underset{(\mathrm{ppm})}{\mathrm{CO}}$ & $\begin{array}{c}\mathrm{CO}_{2} \\
(\mathrm{ppm})\end{array}$ & $\begin{array}{r}\mathrm{HCN} \\
(\mathrm{ppm})\end{array}$ & $\begin{array}{c}\mathrm{O}_{2} \\
(\%)\end{array}$ & $\begin{array}{l}\mathrm{N} \text {-Gas } \\
\text { value }\end{array}$ \\
\hline NIST \#1 & $\begin{array}{c}25 \\
(21-29)^{c}\end{array}$ & $\begin{array}{c}1600 \\
(1300-1800)^{d}\end{array}$ & $\begin{array}{c}28800 \\
(24500-33300)\end{array}$ & $\begin{array}{c}120 \\
(100-130)\end{array}$ & $\begin{array}{c}17.3 \\
(17.9-16.8)\end{array}$ & $\begin{array}{c}1.2^{\mathrm{e}} \\
(0.9-1.5) \\
1.3^{\mathrm{f}}\end{array}$ \\
\hline NIST \#2 & $\begin{array}{c}26 \\
(24-29)\end{array}$ & $\begin{array}{c}1700 \\
(1500-1900)\end{array}$ & $\begin{array}{c}31100 \\
(28800-34700)\end{array}$ & $\begin{array}{c}110 \\
(100-120)\end{array}$ & $\begin{array}{c}17.0 \\
(17.2-16.5)\end{array}$ & $\begin{array}{c}1.3^{\mathrm{c}} \\
(1.1-1.4) \\
1.3^{\mathrm{f}}\end{array}$ \\
\hline Lab \#3 & $\begin{array}{c}25 \\
(23-25)\end{array}$ & NDPh & NDP & NDP & NDP & NDP \\
\hline $\mathrm{Lab} \# 4$ & $\begin{array}{c}26 \\
(23-30)\end{array}$ & $\begin{array}{c}2200 \\
(1900-2100)\end{array}$ & $\begin{array}{c}36400 \\
(32800-41200)\end{array}$ & $\begin{array}{c}90 \\
(80-100)\end{array}$ & $\begin{array}{c}17.8 \\
(18.1-17.4)\end{array}$ & $\begin{array}{c}1.3^{\circ} \\
(1.2-1.5) \\
1.3^{f}\end{array}$ \\
\hline $\mathrm{Lab} \# 5$ & $\begin{array}{c}41 \\
(38-44)\end{array}$ & $\begin{array}{c}2500 \\
(2300-2700)\end{array}$ & $\begin{array}{c}42100 \\
(39100-45000)\end{array}$ & $N M^{i}$ & $\begin{array}{c}18.6 \\
(18.7-18.4)\end{array}$ & $\mathrm{NC}^{\mathbf{j}}$ \\
\hline
\end{tabular}

Time-integrated average concentration over the $30 \mathrm{~min}$ exposure period calculated at the $L C_{50}$ value. Based on the least squares analysis of the average $\mathbf{3 0}$ min gas concentrations at each mass loading tested.

${ }^{\mathrm{b}}$ Based on deaths which occurred within- and post-exposure.

c $95 \%$ confidence limits on $L C_{50}$ value, computed using the method of Litchfield and Wilcoxon [13].

d The gas concentrations calculated at the low and high $95 \%$ confidence limits of the $L C_{50}$.

c Based on a least squares analysis of the N-Gas values for each experiment as a function of the mass loading. N-Gas value is that found at the $L C_{50}$.

${ }^{8}$ Based on gas concentrations provided in this table.

${ }^{\text {h }} \mathrm{NDP}$ - no data provided.

${ }^{i} \mathrm{NM}-$ not measured.

i NC-not calculated due to lack of HCN data.

This evaluation of SRM 1007A showed (with one exception) that there was good reproducibility of results across laboratories (i.e., the $L C_{50}$ values from the different laboratories were within the 95\% confidence limits of the other laboratories). These results agree with our prior and much more extensive interlaboratory evaluation that was conducted on the cup furnace smoke toxicity method [5]. Although this interlaboratory evaluation was conducted with ABS SRM 1007A prior to the realization that the supply was limited, it was not considered necessary to repeat the interlaboratory evaluation with the new material, since the new material chosen to replace ABS SRM 1007A was designed to have a similar formulation.

\subsection{Intralaboratory Evaluation}

Six series of experiments were conducted at NIST on ABS 5 to examine the repeatability of results. Three series were in the nonflaming combustion mode and three were in the flaming combustion mode. Each series consisted of multi- ple experiments (designated by (n) in Tables 5 and 6). The $L C_{50}$ values were determined for each series for the deaths occurring during the $30 \mathrm{~min}$ exposures and for the deaths that occurred during the $30 \mathrm{~min}$ exposures plus the $14 \mathrm{~d}$ post-exposure observation period. The within-exposure results are given in Table 5 and the within plus post-exposure results are given in Table 6. The chemical analytical results for each gas were plotted against the concentration of material loaded into the furnace [mass loading/chamber volume $\left(\mathrm{g} / \mathrm{m}^{3}\right)$ ] and the gas concentrations at the $L C_{50}$ values were determined by a least squares linear regression analysis of the data. Tables 5 and 6 provide the calculated $L C_{50}$ values, the calculated gas concentrations at the $L C_{50}$ s, and two sets of $\mathrm{N}-\mathrm{Gas}$ values at the $L C_{50} \mathrm{~S}$; one set of $\mathrm{N}-\mathrm{Gas}$ values was determined from a least squares linear regression analysis of the data from the individual experiments and the other set of $\mathrm{N}-\mathrm{Gas}$ values was calculated from the gas concentrations presented in Tables 5 and 6 . The data shown in Tables 5 and 6 indicate the good repeatability of results obtained with ABS 5. 
Table 5. Intralaboratory evaluation of ABS 5. Within-exposure NIST Chemical data' at the $L C_{50}$ value

\begin{tabular}{|c|c|c|c|c|c|c|c|c|c|}
\hline $\begin{array}{l}\text { Series \# } \\
(\mathrm{n})^{t}\end{array}$ & $\begin{array}{l}L C_{s 0} \\
\left(\mathrm{~g} / \mathrm{m}^{3}\right)\end{array}$ & $\begin{array}{c}\text { CO } \\
\text { (ppm) }\end{array}$ & $\begin{array}{c}\mathrm{CO}_{2} \\
(\mathrm{ppm})\end{array}$ & $\begin{array}{l}\mathrm{HCN} \\
\text { (ppm) }\end{array}$ & $\begin{array}{c}\mathrm{O}_{2} \\
(\%)\end{array}$ & $\begin{array}{l}\mathrm{NO}_{x} \\
(\mathrm{ppm})\end{array}$ & $\begin{array}{l}\text { No } \\
\text { (ppm) }\end{array}$ & $\begin{array}{c}\mathrm{NO}_{2} \\
(\mathrm{ppm})\end{array}$ & $\begin{array}{l}\mathrm{N} \text {-Gas } \\
\text { value }\end{array}$ \\
\hline \multicolumn{10}{|c|}{ Nonflaming mode } \\
\hline $1(6)$ & $62(53-71)^{b}$ & $420(360-480)^{c}$ & $3490(3060-3910)^{c}$ & $220(190-250)^{c}$ & $20.4(20.5-20.3)^{c}$ & NMt & NM & NM & $\begin{array}{c}1.2^{\mathrm{d}}(1.0-1.5) \\
1.2^{\mathrm{e}}\end{array}$ \\
\hline $2(5)$ & $54(49-60)$ & $420(380-470)$ & $3800(3500-4170)$ & $210(190-240)$ & $20.3(20.4-20.3)$ & $\mathbf{N D}^{\mathrm{h}}$ & ND & ND & $\begin{array}{c}1.1(1.1-1.2) \\
1.2\end{array}$ \\
\hline $3(4)$ & $60(56-64)$ & $440(410-460)$ & $3400(3210-3590)$ & $220(200-230)$ & $20.4(20.4-20.3)$ & $\mathbf{N M}$ & NM & NM & $\begin{array}{c}1.2(1.1-1.3) \\
1.2\end{array}$ \\
\hline \multicolumn{10}{|c|}{ Flaming mode } \\
\hline $1(7)$ & $29(28-31)$ & $1900(1840-2030)$ & $32200(31100-34300)$ & $160(150-170)$ & $16.7(16.8-16.4)$ & $130(130-140)^{\epsilon}$ & $110(110-120)^{c}$ & $17(17-19)$ & $\begin{array}{c}1.5(1.4-1.6) \\
1.5\end{array}$ \\
\hline $2(6)$ & $28(26-30)$ & $1900(1760-2030)$ & $34200(31800-36600)$ & $150(140-160)$ & $16.5(16.9-16.2)$ & $120(120-130)$ & $110(110-120)$ & $18(16-19)$ & $\begin{array}{c}1.3(1.3-1.4) \\
1.4\end{array}$ \\
\hline $3(7)$ & $27(26-28)$ & $1780(1710-1840)$ & $33700(32500-34900)$ & $150(150-160)$ & $16.5(16.7-16.3)$ & $120(120-130)$ & $100(95-100)$ & $18(17-19)$ & $\begin{array}{c}1.4(1.4-1.4) \\
1.4\end{array}$ \\
\hline
\end{tabular}

"Time-integrated average concentration over the 30 min exposure period calculated at the $L C_{s 0}$ value. Based on the least squares analysis of the average $30 \mathrm{~min}$ gas concentrations at each mass loading tested.

balues in parenthesis are the $95 \%$ confidence limits of the $L C_{50}$ value.

- Values in parenthesis are the gas concentrations calculated at the low and high $95 \%$ confidence limits of the $L C_{51 s}$.

d Based on least squares analysis of $\mathrm{N}$-Gas values at each of the mass loadings.

- Based on gas concentrations provided in this table.

I $(\mathrm{n})$ - number of experiments in each series of tests.

- NM-not measured.

"ND-not detected based on two experiments.

Table 6. Intralaboratory evaluation of ABS 5 . Within plus post-exposure NIST chemical data" at the $L C_{50}$

\begin{tabular}{|c|c|c|c|c|c|c|c|c|c|}
\hline $\begin{array}{c}\text { Series \#\# } \\
(n)^{\mathrm{f}}\end{array}$ & $\begin{array}{c}L C_{50} \\
\left(g^{\prime} m^{3}\right)\end{array}$ & $\begin{array}{c}\mathrm{CO} \\
(\mathrm{ppm})\end{array}$ & $\begin{array}{c}\mathrm{CO}_{2} \\
(\mathrm{ppm})\end{array}$ & $\begin{array}{l}\mathrm{HCN} \\
\text { (ppm) }\end{array}$ & $\begin{array}{l}\mathrm{O}_{2} \\
(\%)\end{array}$ & $\begin{array}{c}\text { NO }_{x} \\
(\mathrm{ppm})\end{array}$ & $\begin{array}{c}\text { No } \\
\text { (ppm) }\end{array}$ & $\begin{array}{c}\mathrm{NO}_{2} \\
(\mathrm{ppm})\end{array}$ & $\begin{array}{l}\mathrm{N} \text {-Gas } \\
\text { value }\end{array}$ \\
\hline \multicolumn{10}{|c|}{ Nonflaming mode } \\
\hline $1(6)$ & $60(55-66)^{b}$ & $410(370-450)^{e}$ & $3390(3160-3670)^{c}$ & $210(190-230)^{c}$ & $20.4(20.4-20.3)^{\mathrm{c}}$ & NME & NM & NM & $\begin{array}{c}1.5^{\mathrm{J}}(1.3-1.8) \\
1.5^{e}\end{array}$ \\
\hline $2(5)$ & $50(48-53)$ & $390(380-420)$ & $3560(3440-3740)$ & $200(190-210)$ & $20.4(20.4-20.4)$ & $\mathrm{ND}^{h}$ & ND & ND & $\begin{array}{c}1.4(1.3-1.4) \\
1.4\end{array}$ \\
\hline $3(4)$ & $56(52-60)$ & $410(380-440)$ & $3210(3020-3400)$ & $200(190-220)$ & $20.4(20.5-20.4)$ & NM & NM & NM & $\begin{array}{c}1.4(1.3-1.6) \\
1.4\end{array}$ \\
\hline
\end{tabular}

Flaming mode

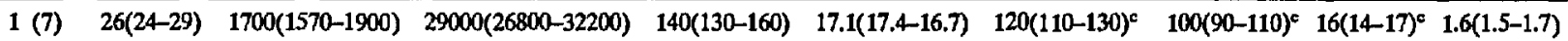

$2(6) \quad 25(24-26) \quad 1690(1630-1760) \quad 30600(29400-31800) \quad 130(130-140) \quad 17.0(17.2-16.9) \quad 110(110-120) \quad 100(100-110) \quad 16(15-16) \quad 1.5(1.5-1.5)$

$3(7) \quad 25(23-27) \quad 1640(1510-1770) \quad 31200(28800-33700) \quad 140(130-150) \quad 16.9(17.2-16.5) \quad 110(100-120) \quad 90(80-100) \quad 16(15-18) \quad 1.6(1.6-1.6)$

- Time-integrated average concentration over the $30 \mathrm{~min}$ exposure period calculated at the $L C_{30}$ value. Based on the least squares analysis of the average $30 \mathrm{~min}$ gas concentrations at each mass loading tested.

- Values in parenthesis are the $95 \%$ confidence limits of the $L C_{50}$ value.

c Values in parenthesis are the gas concentrations calculated at the low and high $95 \%$ confidence limits of the $L C_{50}$.

${ }^{d}$ Based on least squares analysis of $\mathrm{N}-\mathrm{Gas}$ values at each of the mass loadings.

- Based on gas concentrations provided in this table.

${ }^{t}(\mathrm{n})$ - number of experiments in each series of tests.

NM-not measured.

h ND-not detected based on two experiments. 


\subsection{Statistical Analysis}

The Computing and Applied Mathematics Laboratory conducted a statistical analysis of the data from ABS 5 which is to be certified and sold by the Standard Reference Materials Program. Individual probit analysis fits were done for each series of experiments. (Three series were conducted to examine the repeatability of the $L C_{50}$ values.) The $L C_{50}$ value was calculated for each series, resulting in three observations of the $L C_{50}$ for each combustion mode and observation time. N-Gas computations were also done on a series-by-series basis. It was important to examine the data on a series-by-series basis since there appeared to be systematic differences between the series for both the probits and the $\mathrm{N}-\mathrm{G}$ as values. For example, Fig. 4, which shows the three series of experiments for the within exposures to the nonflaming combustion mode, indicates that one series has a different relationship between the N-Gas values and the mass loading/ chamber volume than the other two series (this can be seen by the fact that the slopes of the fitted lines are different for each series). If such systematic differences exist between series, one grand fit to all the data for a given mode and observation period might produce a biased estimate of the $L C_{50}$ value or the corresponding N-Gas value.

The results of this statistical analysis are presented in Table 7 and in Figs. 4 through 7. In these figures, a straight line through the origin was fit by

Table 7. Statistical analysis of $L C_{50}$ values and $N-G a s$ values for ABS 5

\begin{tabular}{|c|c|c|c|c|}
\hline $\begin{array}{l}\text { Combustion } \\
\text { mode }\end{array}$ & $\begin{array}{l}\text { Observation } \\
\text { time }\end{array}$ & Test series & $\begin{array}{c}L C_{50} \text { values } \\
\left(\mathrm{g} / \mathrm{m}^{3}\right)\end{array}$ & $\begin{array}{l}\text { N-Gas } \\
\text { values }\end{array}$ \\
\hline \multirow[t]{6}{*}{ Flaming } & $W^{*}$ & 1 & 28 & 1.4 \\
\hline & & 2 & 26 & 1.3 \\
\hline & & 3 & 28 & 1.4 \\
\hline & $W E \& E^{b}$ & 1 & 26 & 1.6 \\
\hline & & 2 & 25 & 1.4 \\
\hline & & 3 & 24 & 1.5 \\
\hline \multirow[t]{6}{*}{ Nonflaming } & WE & 1 & 62 & 1.2 \\
\hline & & 2 & 51 & 1.1 \\
\hline & & 3 & 60 & 1.2 \\
\hline & WE \& PE & 1 & 57 & 1.5 \\
\hline & & 2 & 48 & 1.3 \\
\hline & & 3 & 55 & 1.4 \\
\hline
\end{tabular}

a WE-deaths occurred within the 30 min exposure.

${ }^{b}$ WE \& PE-combined deaths that occurred either within the $30 \mathrm{~min}$ exposure and/or the $14 \mathrm{~d}$ post-exposure observation period. least squares linear regression analysis of the $\mathrm{N}$ Gas values as a function to the mass loading/chamber volume for each series. Then the $\mathrm{N}-\mathrm{Gas}$ value at the $L C_{50}$ value for that series was determined resulting in three observations of the $\mathrm{N}$-Gas value at the $L C_{50}$ (one for each series) for each combustion mode and observation period.

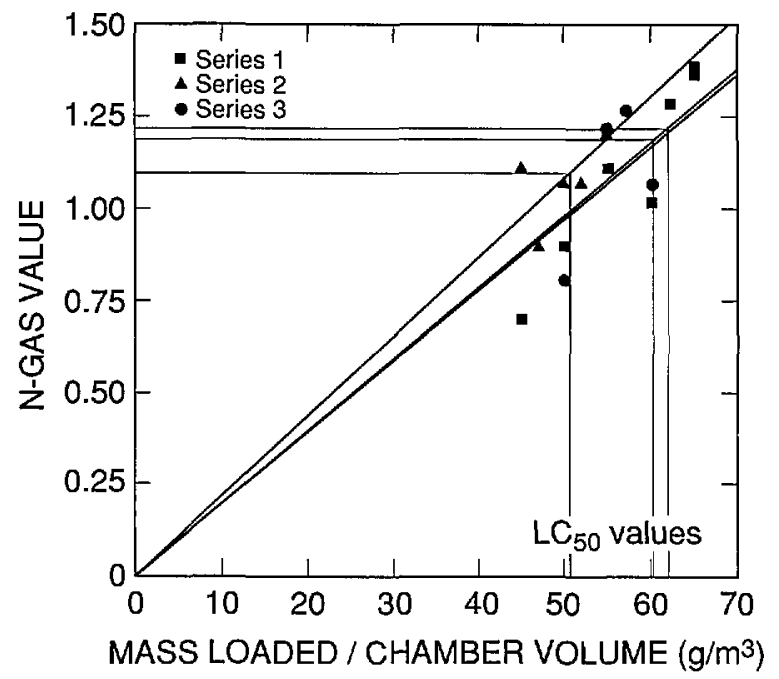

Fig. 4. N-Gas values as a function of concentration [i.e., mass of material loaded into the cup furnace divided by the exposure chamber volume $\left.\left(\mathrm{g} / \mathrm{m}^{3}\right)\right]$ for the three separate series of tests on ABS 5. Nonflaming mode, within exposure effects.

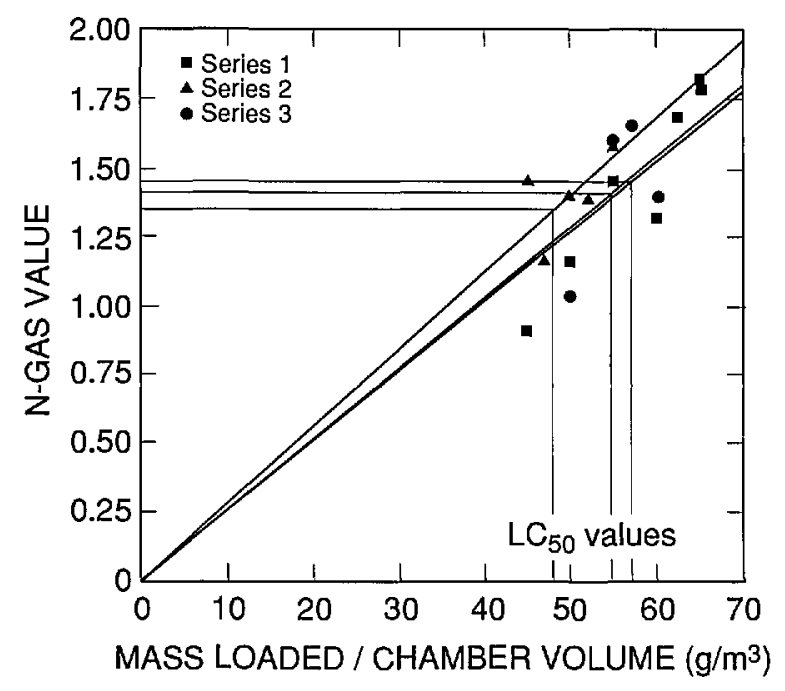

Fig. 5. N-Gas values as a function of concentration [i.e., mass of material loaded into the cup furnace divided by the exposure chamber volume $\left.\left(\mathrm{g} / \mathrm{m}^{3}\right)\right]$ for the three separate series of tests on ABS 5. Nonflaming mode, within plus post-exposure effects. 


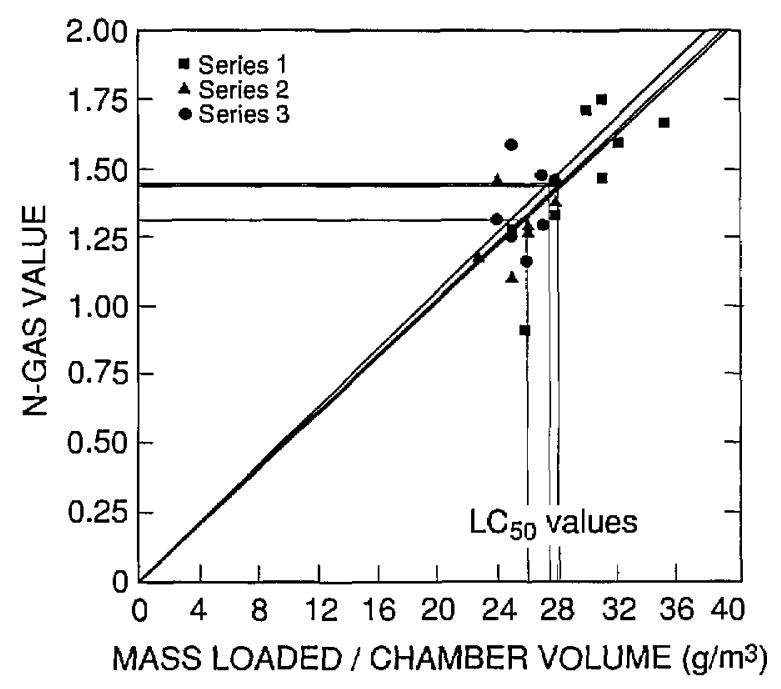

Fig. 6. N-Gas values as a function of concentration [i.e., mass of material loaded into the cup furnace divided by the exposure chamber volume $\left.\left(\mathrm{g} / \mathrm{m}^{3}\right)\right]$ for the three separate series of tests on ABS 5. Flaming mode, within exposure effects.

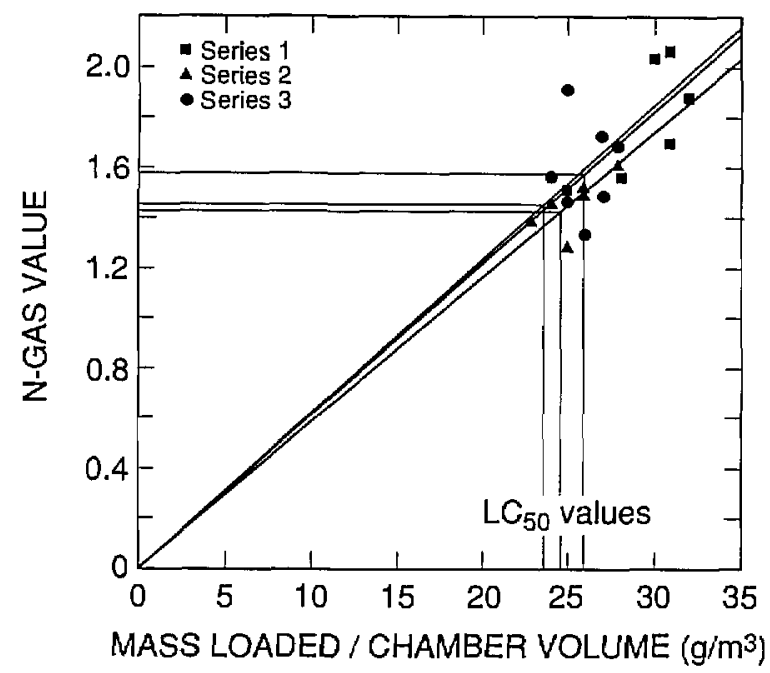

Fig. 7. N-Gas values as a function of concentration [i.e., mass of material loaded into the cup furnace divided by the exposure chamber volume $\left.\left(\mathrm{g} / \mathrm{m}^{3}\right)\right]$ for the three separate series of tests on ABS 5. Flaming mode, within plus post-exposure effects.
The variation in the three observations incorporates both the uncertainty with each fit and the differences between series. Therefore, the mean and a confidence interval for the mean based on the three observations for each combustion mode and observation period summarize the $L C_{50}$ and $\mathrm{N}$-Gas values, giving the user of the SRM our best estimates of the true values for the material and how well we know them (Table 8). The intervals provided in Table 8 are the $95 \%$ confidence intervals based on two degrees of freedom. The $L C_{50}$ and N-Gas values shown in Table 8 are the values that will be provided on the SRM certificate.

\section{Discussion}

An acrylonitrile-butadiene-styrene (ABS) has been evaluated and submitted for certification for use as a standard reference material (SRM 1048) for the cup furnace smoke toxicity method. An interlaboratory evaluation conducted by four laboratories on a comparable ABS material indicated good reproducibility of $L C_{50}$ values (with one exception in the flaming mode) and N-Gas values across laboratories. This interlaboratory evaluation showed that the determination of the autoignition temperature of the test material was variable, but that if the experiments are conducted $25^{\circ} \mathrm{C}$ above (flaming) and below (nonflaming) the individually determined autoignition temperatures, the chemistry and toxicity results were comparable between laboratories. These results indicate that the autoignition temperature should be determined by each laboratory and should not be included in the certified values of the SRM. In other words, the temperatures at which the experiments are conducted are normalized by the material and not by the temperature reading which could vary due to furnace construction, thermocouple placement or other differences between laboratory equipment.

Table 8. Mean $L C_{50}$ and $\mathrm{N}-\mathrm{Gas}$ values plus their $95 \%$ confidence limits for $\mathrm{ABS} 5$

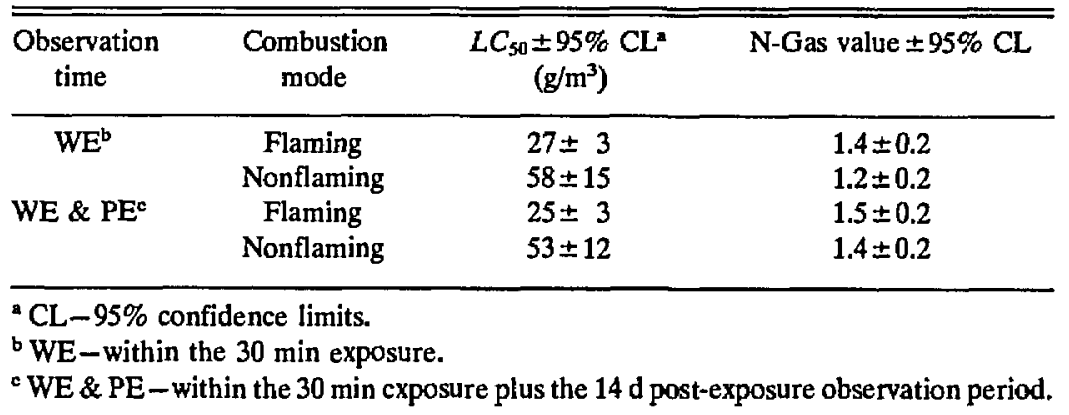


Both the mean $L C_{50}$ values and the N-Gas values \pm their respective $95 \%$ confidence limits are provided in Table 8 and can be used with this SRM to calibrate the method and assure the user that the data that they obtained with this procedure is within the expected bounds. Since the N-Gas values were determined at the $L C_{50}$, the N-Gas values can be used instead of determining the complete $L C_{50}$ value for each combustion mode (flaming or nonflaming) and observation period (within the exposure or within plus the post-exposure period). Utilization of the $\mathrm{N}-\mathrm{G}$ as values rather than determination of each $L C_{50}$ value for comparison with the certified $L C_{50}$ values has the advantages of reducing the number of needed experimental animals, the time necessary to complete the calibration tests, and the expense.

It is left to the user's discretion whether complete $L C_{50}$ values should be determined or if the $\mathrm{N}$-Gas approach should be used. We recommend the latter approach. In the N-Gas approach, both the chemical (N-Gas values) and toxicological results (actual lethalities at the certified $L C_{50}$ values) are compared to the certified values. To use the $\mathrm{N}$-Gas approach, one needs to decompose the SRM at the certified $L C_{50}$ values in either the flaming or nonflaming mode, measure the concentrations of pertinent gases, namely, $\mathrm{CO}, \mathrm{CO}_{2}, \mathrm{HCN}$, and $\mathrm{O}_{2}$, and determine the N-Gas value. Comparison of this value with the $\mathrm{N}$-Gas value provided in the SRM certificate will show if the chemical results agree with the certified results. To determine if the toxicological results are comparable, the mass of material equivalent to the certified $L C_{50}$ is decomposed in the presence of the rats as described in Ref. [4]. One or two experiments should indicate if the animals respond as expected (i.e., two to five rats die either within the $30 \mathrm{~min}$ exposure or within the 30 min exposure plus the $14 \mathrm{~d}$ post-exposure period, depending on which observation period is of interest).

It should be noted that with this particular material, the $\mathrm{N}-\mathrm{G}$ as values at the $L C_{50}$ values are higher than unity, especially in the flaming mode. N-Gas values lower than unity indicate that toxic gases other than $\mathrm{CO}, \mathrm{CO}_{2}, \mathrm{HCN}$, and $\mathrm{O}_{2}$ may be contributing to the toxic atmospheres (i.e., making the combustion atmosphere more toxic than predicted). N-Gas values higher than unity indicate that one or more gases may be acting as a toxicological antagonist (i.e., making the combustion atmosphere less toxic than predicted). In our studies at NIST, we have found N-Gas values are higher than expected in those cases where the material produces a significant amount of $\mathrm{HCN}$. Our recent data (to be published) indicates that in these cases, $\mathrm{NO}_{x}$ is also formed. As expected, $\mathrm{NO}_{x}$ was found in the combustion atmospheres of the ABS tested for this SRM (Tables 5 and 6). Our studies with $\mathrm{NO}_{2}$ indicate that exposure to $\mathrm{NO}_{2}$ increases the methemoglobin levels in the blood [24]. It is well known that methemoglobin acts as an antidote for cyanide poisoning by binding the $\mathrm{CN}^{-}$and preventing it from being transferred to the tissues where the toxic insult occurs. We believe, therefore, that the N-Gas values at the $L C_{50}$ values of this $A B S$ are higher than expected because $\mathrm{NO}_{x}$ causes the formation of methemoglobin which acts as an antidote for the HCN (i.e., an antagonistic effect occurs). An $\mathrm{N}$-Gas equation including $\mathrm{NO}_{2}$ is being tested, but for the purposes of the use of this SRM is not necessary. The user can employ the certified N-Gas values and thus, will not be required to monitor $\mathrm{NO}_{x}$ which requires additional analytical equipment that might not be readily available in many laboratories.

With SRM 1048, an investigator can calibrate both the chemical (based on the certified N-Gas values) and toxicological results (based on the certified $\mathrm{N}$-Gas or $L C_{50}$ values) from two combustion modes (flaming and nonflaming) in the cup furnace smoke toxicity method. If the experimental values fall within the $95 \%$ confidence limits of the certified values of this SRM, investigators can be confident that they are using the equipment properly.

\section{Conclusions}

A standard reference material ABS SRM 1048 has been developed to calibrate the cup furnace smoke toxicity method. The SRM material chosen is an acrylonitrile-butadiene-styrene (ABS) which is the same material used for SRM 1007B that has been recently certified for calibration of the flaming mode of the ASTM E-662 and NFPA 258 Smoke Density Chamber methods. Certified values plus their $95 \%$ confidence limits are provided for both the $L C_{50}$ values and the N-Gas values for two combustion modes (flaming and nonflaming) and two observation periods (within the $30 \mathrm{~min}$ exposure or within the $30 \mathrm{~min}$ exposure plus a $14 \mathrm{~d}$ postexposure period). The certified $L C_{50}$ values plus $95 \%$ confidence intervals (in $\mathrm{g} / \mathrm{m}^{3}$ ) are $27 \pm 3$ (30 $\mathrm{min}$, flaming); $25 \pm 3$ (30 min $+14 \mathrm{~d}$, flaming); $58 \pm 15$ ( $30 \mathrm{~min}$, nonflaming); and $53 \pm 12$ (30 $\min +14 \mathrm{~d}$, nonflaming). The certified $\mathrm{N}-\mathrm{Gas}$ values plus $95 \%$ confidence intervals are $1.4 \pm 0.2$ (30 
min, flaming); $1.5 \pm 0.2$ (30 min $+14 \mathrm{~d}$, flaming); $1.2 \pm 0.2$ (30 min, nonflaming); and $1.4 \pm 0.2$ (30 min $+14 \mathrm{~d}$; nonflaming). It is recommended that the users conserve experimental animals, time and expense by using the $\mathrm{N}$-Gas approach to calibrate their system rather than conducting the complete determination of the $L C_{50}$ values.

\section{Acknowledgments}

The authors acknowledge the help of Mr. J. R. Lawson, who worked with the manufacturer to assure that the ABS materials would meet the necessary specifications. We also wish to acknowledge Mr. Richard Seward, now retired from the Office of Standard Reference Materials, who provided invaluable advice during the initial phases of this work. Ms. Nancy Eller is also acknowledged for her expert technical assistance in these experiments. The participation of Mobay Corporation, Southwest Research Institute, and the U.S. Testing Company, Inc. in the interlaboratory evaluation is greatly appreciated.

\section{References}

[1] Fire in the United States, Second Ed., Federal Emergency Management Agency, FEMA 22 (July 1982).

[2] M. M. Birky, B. M. Halpin, Y. H. Caplan, R. S. Fisher, J. M. McAllister, and A. M. Dixon, Fire fatality study, Fire Mater. 3, 211-217 (1979).

[3] H. L. Kaplan, A. F. Grand, and G. E. Hartzell, Combustion Toxicology, Principles and Test Methods, Technomic Publishing Co., Inc., Lancaster, PA (1983).

[4] B. C. Levin, A. J. Fowell, M. M. Birky, M. Paabo, A. Stolte, and D. Malek, Further development of a test method for the assessment of the acute inhalation toxicity of combustion products. NBSIR 82-2532, Natl. Bur. Stand. (U.S.), Gaithersburg, MD (1982).

[5] B. C. Levin, M. Paabo, and M. M. Birky, An interlaboratory evaluation of the National Bureau of Standards Test Method for assessing the acute inhalation toxicity of combustion products. NBSIR 83-2678, Natl. Bur. Stand. (U.S.), Gaithersburg, MD (1983).

[6] Y. C. Alarie and R. C. Anderson, Toxicologic and acute lethal hazard evaluation of thermal decomposition products of synthetic and natural polymers. Tox. Appl. Pharm. 51, 341-362 (1979).

[7] New York State Uniform Fire Prevention and Building Code, Article 15, Part 1120, Combustion toxicity testing and regulations for implementing building materials and finishes; fire gas toxicity data file. New York State, Department of State, Office of Fire Prevention and Control, Albany, NY 12231 (December 16, 1986).
[8] Navy Military Standard, Fire and toxicity test methods and qualification procedure for composite material systems used in hull, machinery applications inside naval submarines. MIL-STD-2031(SH), prepared by the Naval Sea Systems Command, (Project 19GP-N007) (March 10, 1988).

[9] Annual Book of ASTM Standards, Volume 4.07, E 662-83, Specific optical density of smoke generated by solid materials. ASTM, Philadelphia, PA (1988).

[10] NFPA 258, Smoke Generation of Solid Materials, National Fire Protection Association, Quincy, MA (1989).

[11] I. M. Kolthoff and E. B. Sandell, Textbook of Quantitative Inorganic Analysis, Second Ed., MacMillan Co., New York, p. 546 (1953).

[12] M. Paabo, M. M. Birky, and S. E. Womble, Analysis of hydrogen cyanide in fire environments. J. Comb. Tox. 6, 99-108 (1979).

[13] J. T. Litchfield and F. Wilcoxon, A simplified method of evaluating dose-effect experiments. J. Pharmacol. Exp. Therapeut. 96, 99-113 (1949).

[14] D. J. Finney, Probit Analysis, 3rd Ed., London Cambridge Press (1971).

[15] B. C. Levin and R. G. Gann, Toxic potency of fire smoke. Chapter 1, Fire and Polymers, Hazards Identification and Prevention, G. L. Nelson, ed., ACS Symposium Series 425, American Chemical Society, Washington, DC (1990).

[16] B. C. Levin, M. Paabo, J. L. Gurman, and S. E. Harris, Effects of exposure to single or multiple combinations of the predominant toxic gases and low oxygen atmospheres produced in fires, Fundamental Appl. Toxicology 9, 236250 (1987).

[17] B. C. Levin, J. L. Gurman, M. Paabo, L. Baier, and T. Holt, Toxicological effects of different time exposures to the fire gases: carbon monoxide or hydrogen cyanide or to carbon monoxide combined with hydrogen cyanide or carbon dioxide, Proceedings of the Ninth Meeting of the U.S.Japan Panel on Fire Research and Safety, Norwood, MA, May 1987. NBSIR 88-3753, Natl. Bur. Stand. (U.S.), Gaithersburg, MD, pp. 368-384 (April, 1988).

[18] B. C. Levin, M. Paabo, J. L. Gurman, H. M. Clark, and M. F. Yoklavich, Further studies of the toxicological effects of different time exposures to the individual and combined fire gases-carbon monoxide, hydrogen cyanide, carbon dioxide and reduced oxygen, Polyurethane 88 , Proceedings of the 31st SPI Conference, Philadelphia, PA, pp. 249-252 (October 1988).

[19] B. C. Levin, M. Paabo, J. L. Gurman, S. E. Harris, and E. Braun, Toxicological interactions between carbon monoxide and carbon dioxide. Toxicology 47, 135-164 (1987).

[20] V. Babrauskas, R. H. Harris, R. G. Gann, B. C. Levin, B. T. Lee, R D. Peacock, M. Paabo, W. Twilley, M. F. Yoklavich, and H. M. Clark, Fire hazard comparison of fire-retarded and non-fire-retarded products. NBS Special Publication 749, Natl. Bur. Stand. (U.S.), Gaithersburg, MD (1988).

[21] E. Braun, S. Davis, J. H. Klote, B. C. Levin, and M. Paabo, Assessment of the fire performance of school bus interior components. NISTIR 4347, Nati. Inst. Stand. Technol., Gaithersburg, MD, July 1990.

[22] E. Braun, R. G. Gann, B. C. Levin, and M. Paabo, Combustion product toxic potency measurements: comparison of a small-scale test and "real-world" fires. J. Fire Sci. 8, 63-79 (1990). 
[23] V. Babrauskas, R. H. Harris, Jr., E. Braun, B. C. Levin, M. Paabo, and R. G. Gann, The role of bench-scale test data in assessing real-scale fire toxicity. NIST Technical Note 1284, Natl. Inst. Stand. Technol, Gaithersburg, MD, January 1991.

[24] B. C. Levin, M. Paabo, L. Highbarger, and N. Eller, Synergistic effects of nitrogen dioxide and carbon dioxide following acute inhalation exposures in rats. NISTIR 89-4105, Natl. Inst. Stand. Technol., Gaithersburg, MD, June 1989.

About the authors: Barbara C. Levin is a project leader and toxicologist in the Fire Toxicity Measurement Group, Fire Measurement and Research Division, Building and Fire Research Laboratory. Maya Paabo is an analytical chemist who recently retired from the National Institute of Standards and Technology. Susannah B. Schiller is a statistician in the Computing and Applied Mathematics Laboratory. 